\title{
Linking Mental Health and After School Systems for Children in Urban Poverty: Preventing Problems, Promoting Possibilities
}

\author{
Stacy L. Frazier - Elise Cappella $\cdot$ Marc S. Atkins
}

Published online: 14 June 2007

(C) Springer Science+Business Media, LLC 2007

\section{Erratum to: Adm Policy Ment Health \& Ment Health} Serv Res

\section{DOI 10.1007/s10488-007-0118-y}

The last sentence in the abstract should have read as follows:

In light of the increasing needs and depleting resources of urban, poor communities, consultation to publicly funded after school programs can contribute to the mental health goals of keeping children safe and supervised, promoting their healthy development through academically and socially enriching activities, and identifying children in need of more intensive mental health services.
The online version of the original article can be found under doi:10.1007/s10488-007-0118-y

S. L. Frazier $(\bowtie) \cdot$ E. Cappella $\cdot$ M. S. Atkins Institute for Juvenile Research, Department of Psychiatry, (M/C 747), The University of Illinois at Chicago, 1747 West Roosevelt Road, Room 155, Chicago, IL 60608, USA

e-mail: sfrazier@psych.uic.edu

E. Cappella

e-mail: ecappella@psych.uic.edu

M. S. Atkins

e-mail: atkins@uic.edu 